\title{
Hubungan Jenis Kelamin, Status Pernikahan, dan Status Pekerjaan dengan Gangguan Ansietas Menyeluruh di Klinik Psikiatri RS dr. Pirngadi Medan
}

\author{
Nining Gilang Sari, Elmeida Effendy, Mustafa Mahmud Amin \\ Departemen Ilmu Kedokteran Jiwa, Fakultas Kedokteran Universitas Sumatera Utara \\ RSUP Haji Adam Malik Medan
}

\begin{abstract}
Abstrak
Gangguan ansietas menyeluruh merupakan bagian penting dari beban global penyakit, dan diproyeksikan sebagai penyebab kedua paling umum kecacatan pada tahun 2020. Gangguan ansietas menyeluruh menyebabkan peningkatan distres dan terganggunya fungsi kehidupan. Penelitian ini merupakan penelitian potong lintang dengan consecutive sampling pada 100 pasien klinik psikiatri Rumah Sakit dr. Pirngadi Medan selama periode 1 Juli hingga 31 Juli 2012. Pengumpulan data dilakukan melalui wawancara menggunakan kuesioner, Mini International Neuropsychiatric Interview for International Classification of Disease-10 (MINI ICD-10), dan dilanjutkan dengan kriteria diagnostik Pedoman Penggolongan dan Diagnosis Gangguan Jiwa di Indonesia III (PPDGJ III) yang digunakan di Indonesia untuk konfirmasi diagnosis. Hasil penelitian ini mengungkapkan, jumlah pasien dengan gangguan ansietas menyeluruh adalah 23\%. Jumlah gangguan ansietas menyeluruh diidentifikasi lebih besar dalam kelompok subjek perempuan (14/23), menikah (13/23), dan bekerja (12/23). Simpulan, tidak ada hubungan jenis kelamin, status pernikahan, dan status pekerjaan dengan gangguan ansietas menyeluruh. [MKB.2014;46(4):216-20]
\end{abstract}

Kata kunci: Gangguan ansietas menyeluruh, klinik psikiatri, MINI ICD-10

\section{Relationship between Gender, Marital Status, Employment Status and Generalized Anxiety Disorder among Patients at the Psychiatry Clinic of Dr. Pirngadi Hospital Medan}

\begin{abstract}
Generalized anxiety disorder constitutes a substantial proportion of the global burden of disease and is projected to be the second most common cause of disability by 2020. This disorder leads to increased distress and impaired life functions. This study was a cross-sectional study with consecutive sampling to 100 patients of the psychiatric clinic of Dr. Pirngadi hospital Medan during the period of July 1st to July31th 2012. Data were collected through interviews using a questionnaire, Mini International Neuropsychiatric Interview for International Classification of Disease-10 (MINI ICD-10) form, followed by the diagnostic criteria of Indonesian Psychiatric Disorder Classification and Diagnosis Guideline III (Pedoman Penggolongan dan Diagnosis Gangguan Jiwa di Indonesia III, PPDGJ III) confirm the diagnosis. Results of this research revealed that the percentage of patients with generalized anxiety disorder was $23 \%$. A higher percentage of generalized anxiety disorder was identified in females group (14 of 23), married respondents (13 of 23) and employed respondents (12of 23). In conclusion, there is no relationship between gender, marital status, employment status and generalized anxiety disorder. [MKB. 2014;46(4):216-20]
\end{abstract}

Key words: Generalized anxiety disorder, MINI ICD-10, psychiatric clinic

\footnotetext{
Korespondensi: Nining Gilang Sari, dr., M.Ked (KJ) Departemen Ilmu Kedokteran Jiwa Fakultas Kedokteran Universitas Sumatera Utara/RSUP Haji Adam Malik Medan, Jalan Bunga Lau No 17 Medan Tuntungan, Medan, mobile 085218009191, e-mailhu9sy@yahoo.com
} 


\section{Pendahuluan}

Ansietas dapat dikonsepkan sebagai suatu respons normal dan adaptif terhadap ancaman. Seseorang yang khawatir mengenai hampir semua keadaan dapat diklasifikasikan sebagai gangguan ansietas menyeluruh. Diagnostic and Statistical Manual of Mental Disorders Fourth Edition Text Revised (DSM-IV-TR) menggambarkan bahwa gangguan ansietas menyeluruh sebagai suatu kecemasan berlebihan dan kekhawatiran mengenai beberapa kejadian atau aktivitas pada sebagian besar hariharinya selama paling kurang 6 bulan. ${ }^{1}$

Berdasarkan atas Pedoman Penggolongan dan Diagnosis Gangguan Jiwa di Indonesia III (PPDGJ III), gambaran esensial gangguan ansietas menyeluruh merupakan ansietas yang menyeluruh dan menetap (bertahan lama), tetapi tidak terbatas pada atau hanya menonjol pada setiap keadaan lingkungan tertentu (misalnya bersifat 'mengambang' atau free floating). Gejala yang dominan sangat bervariasi, tetapi keluhan tegang berkepanjangan, gemetar, ketegangan otot, berkeringat, kepala terasa ringan, palpitasi, pusing kepala, dan keluhan epigastrik merupakan keluhan yang paling lazim dijumpai. Ketakutan bahwa dirinya atau anggota keluarganya akan menderita sakit atau akan mengalami kecelakaan dalam waktu dekat, merupakan keluhan yang sering diucapkan, bersamaan dengan berbagai kekhawatiran dan firasat lain. ${ }^{2}$

Gangguan ansietas menyeluruh merupakan proporsi yang besar beban penyakit di dunia dan diproyeksikan sebagai penyebab disabilitas nomor dua pada tahun $2020 .{ }^{3}$ Gangguan ansietas menyeluruh merupakan salah satu kondisi yang telah diteliti dalam pusat pelayanan primer. International WHO Multi-center Study pada Psychological Problems in General Health Care mengungkapkan bahwa kurang lebih 7,9\% pengunjung pusat pelayanan primer ditemukan memiliki kriteria diagnostik untuk gangguan ansietas menyeluruh berdasarkan atas DSM-III-R. Dalam penelitian yang dilakukan oleh Lieb dkk., ${ }^{4}$ dari hampir 2.000 orang yang mendatangi 5 pusat pelayanan primer di Eropa, 22\% mengeluhkan masalah berhubungan dengan ansietas didiagnosis gangguan ansietas menyeluruh mempergunakan composite international diagnostic interview (CIDI).

Rasio wanita gangguan ansietas menyeluruh bila dibandingkan dengan laki-laki adalah 2:1, namun rasio wanita yang mendapat pengobatan gangguan tersebut dibandingkan dengan lakilaki adalah 1:1. ${ }^{1}$ Berdasarkan penelitian yang dilakukan oleh Araya dkk. ${ }^{5}$ di Chile, dilaporkan bahwa wanita mempunyai angka prevalensi yang lebih tinggi daripada pria dalam gangguan ansietas menyeluruh. Menurut Yonkers dkk., ${ }^{6}$ wanita dengan gangguan ansietas menyeluruh akan lebih sering daripada pria untuk memiliki riwayat tambahan gangguan ansietas. ${ }^{6}$

Dalam penelitian yang dilakukan oleh AlSaffar dan Saeed ${ }^{7}$ gangguan ansietas menyeluruh lebih banyak dijumpai pada wanita sebesar $42,8 \%$ bila dibandingkan dengan pria, status pernikahan bercerai $63,5 \%$, dan status pekerjaan yang tidak bekerja 52,3\%. Di Indonesia belum ada penelitian sebelumnya tentang prevalensi gangguan ansietas menyeluruh pada pelayanan rawat jalan klinik psikiatri. Berdasarkan presurvei yang telah dilakukan oleh peneliti dalam rentang waktu 1 Januari hingga 30 Juni 2011, ditemukan bahwa $36,92 \%$ terdiagnosis dengan gangguan ansietas menyeluruh dari seluruh pasien yang datang berobat ke klinik psikiatri RS dr. Pirngadi Medan dengan mengeksklusikan pasien psikotik, pasien dengan penyalahgunaan zat, serta pasien dengan penyakit fisik yang mengharuskannya berobat ke bagian lain.

Mini International Neuropsychiatric Interview (MINI) versi International Classification of Disease (ICD-10) yang akan digunakan dalam penelitian ini adalah suatu wawancara terstruktur yang sangat singkat untuk dapat mendiagnosis gangguan psikiatrik utama dari International Classification of Diseases. ${ }^{8}$ Metode MINI ICD-10 dipilih karena validitas dan reliabilitas MINI ICD10 telah teruji dengan menggunakan composite international diagnosis interview (CIDI) dan structured clinical interview for DSM (SCID) sebagai baku emas. Selain itu, MINI ICD-10 merupakan suatu wawancara klinik, terstruktur, dan lebih singkat daripada wawancara penelitian yang biasa digunakan, namun lebih komprehensif daripada uji screening serta tidak menimbulkan bias kultural.9-11

MINI mengikuti kriteria DSM-IV dan ICD10 untuk gangguan psikiatrik, mengandung 130 pertanyaan dan menyaring 17 gangguan pada Axis I, dengan modul bunuh diri dan kepribadian antisosial. ${ }^{12}$ Gangguan Axis I yang termasuk dalam MINI dipilih berdasarkan prevalensi 12 bulan yang dilaporkan oleh Epidemiologic Catchment Area Study dan National Comorbidity Survey. ${ }^{13}$ MINI tidak memerlukan waktu lebih dari 15 menit untuk pengisian. Gangguan yang didiagnosis oleh MINI dikaitkan dengan kerangka waktu yang dibutuhkan untuk menegakkan diagnosis pada gangguan ansietas menyeluruh adalah kondisi subjek dalam 6 bulan terakhir. ${ }^{14}$

Tujuan lain penelitian ini untuk menemukan hubungan gangguan ansietas menyeluruh dengan karakteristik demografik berupa jenis kelamin, status pekerjaan, dan status pernikahan. 
Nining G.: Hubungan Jenis Kelamin, Status Pernikahan, dan Status Pekerjaan dengan Gangguan Ansietas Menyeluruh

Tabel 1 Karakteristik Demografik Subjek

\begin{tabular}{llc}
\hline & Karakteristik Responden & Jumlah (\%) \\
\hline \multirow{2}{*}{ Jenis kelamin } & Perempuan & 47 \\
& Laki-laki & 53 \\
\multirow{2}{*}{ Status pernikahan } & Cerai/pisah & 21 \\
& Belum menikah & 21 \\
Status pekerjaan & Menikah & 58 \\
& Tidak bekerja & 53 \\
\hline
\end{tabular}

\section{Metode}

Penelitian ini merupakan penelitian potong lintang untuk menilai hubungan jenis kelamin, status pernikahan, dan status pekerjaan terhadap gangguan ansietas menyeluruh. Cara pemilihan sampel yaitu non probability sampling jenis consecutive sampling dengan besar subjek 100 orang. Semua subjek penelitian telah diminta mengisi persetujuan secara tertulis untuk ikut serta dalam penelitian setelah terlebih dahulu diberi penjelasan yang terperinci dan jelas.

Subjek penelitian yang diikutsertakan pada penelitian ini adalah pasien yang datang ke klinik psikiatri RS dr. Pringadi Medan periode 1 Juli hingga 31 Juli 2012. Kriteria inklusi subjek penelitian adalah berusia 18-59 tahun, dan kooperatif, serta bersedia untuk diwawancara.

Untuk menilai gangguan ansietas menyeluruh dipergunakan penilaian MINI ICD-10 kemudian dilanjutkan dengan kriteria diagnostik dari PPDGJ III. Untuk menilai ada tidaknya hubungan gangguan ansietas menyeluruh dengan usia, jenis kelamin, dan tingkat pendidikan digunakan uji chi-kuadrat. Pengolahan dan analisis data yang diperoleh dilakukan dengan program statistical product and service solutions (SPSS).

\section{Hasil}

Data karakteristik demografik pasien yang berobat ke poliklinik psikiatri RS dr. Pirngadi Medan dapat dilihat pada Tabel 1, pasien yang berobat ke klinik psikiatri di RS dr. Pirngadi Medan terbanyak adalah laki-laki sebanyak 53\%, memiliki status pernikahan menikah sebanyak $58 \%$, dan memiliki status pekerjaan tidak bekerja sebanyak $53 \%$. Proporsi terjadinya gangguan ansietas menyeluruh pasien yang datang berobat ke poliklinik psikiatri RS Dr. Pirngadi Medan adalah $23 \%$.

Gangguan ansietas menyeluruh terbanyak pada wanita yaitu 14 dari $23(\mathrm{p}=0,200)$, status pernikahan menikah yaitu 13 dari $23(\mathrm{p}=0,371)$, dan status pekerjaan bekerja yaitu 12 dari 23 $(\mathrm{p}=0,743)$. Hasil analisis uji chi-kuadrat tidak ditemukan hubungan signifikan jenis kelamin,

Tabel 2 Hubungan Jenis Kelamin, Status Pernikahan, dan Status Pekerjaan dengan Kejadian Gangguan Ansietas Menyeluruh

\begin{tabular}{lccc}
\hline & \multicolumn{2}{c}{ Gangguan Ansietas Menyeluruh } & p \\
\cline { 2 - 3 } & Positif & Negatif & \\
\hline Jenis kelamin & 14 & 33 & 0,200 \\
Wanita & 9 & 44 & \\
Laki-laki & & & \\
Status pernikahan & 7 & 14 & 0,371 \\
Cerai/pisah/meninggal mati & 3 & 17 & \\
Belum menikah & 13 & 45 & \\
Menikah & & & 0,743 \\
Status pekerjaan & 11 & 42 & \\
Tidak bekerja & 12 & 35 & \\
Bekerja & & & \\
\hline
\end{tabular}


status pernikahan, dan status pekerjaan dengan gangguan ansietas menyeluruh dengan nilai $\mathrm{p}>0,05$.

\section{Pembahasan}

Hasil analisis itu memperlihatkan tidak terdapat hubungan yang bermakna antara jenis kelamin dan gangguan ansietas menyeluruh. Keadaan ini tidak sesuai dengan penelitian yang dilakukan oleh Al-Saffar dan Saeed ${ }^{7}$ bahwa wanita lebih sering didiagnosis sebagai gangguan ansietas menyeluruh bila dibandingkan dengan laki-laki. Peningkatan gangguan ansietas menyeluruh pada wanita didasarkan bahwa wanita lebih mudah mengakui telah mengalami ansietas. Pada lakilaki gangguan ansietas yang menyeluruh dan penyalahgunaan alkohol terdiagnosis oleh karena gangguan yang berhubungan dengan alkohol daripada gangguan oleh karena ansietas. Wanita berbagai kalangan merupakan subjek dengan berbagai macam keadaan sosial, yang dapat predisposisi menjadi kondisi psikiatri seperti gangguan ansietas yang menyeluruh. ${ }^{7}$ Penelitian oleh Scott dkk. ${ }^{15}$ memperlihatkan bahwa wanita lebih sering mengalami distres terutama karena masalah pernikahannya.

Survei epidemiologi yang dilakukan Kessler dkk. ${ }^{16}$ memperlihatkan terdapat hubungan antara gangguan ansietas menyeluruh dan jenis kelamin wanita. Analisis prospektif yang dilakukan oleh Yonkers dkk. ${ }^{17}$ menemukan bahwa variabel ini tidak berhubungan signifikan dengan gangguan ansietas yang menyeluruh. Konsisten dengan penemuan ini, analisis dari data epidemiologi cross sectional WHO International Consortium dalam Psychiatric Epidemiology memperlihatkan bahwa tidak ada hubungan yang signifikan antara jenis kelamin dan gangguan ansietas menyeluruh pada responden, setelah usia onset dan waktu setelah onset dikontrol. ${ }^{16}$

Hasil penelitian menunjukkan tidak terdapat hubungan bermakna antara status pernikahan dan gangguan ansietas menyeluruh. Keadaan ini tidak sesuai dengan penelitian yang dilakukan Al-Saffar dan Saeed ${ }^{7}$ bahwa terdapat hubungan antara status pernikahan dan gangguan ansietas menyeluruh dengan angka kejadian tertinggi adalah bercerai. Hal ini mungkin terjadi karena kesulitan yang dihadapi dalam perceraian atau perpisahan dan dukungan yang kurang, serta rasa percaya diri yang rendah dalam menghadapi masalah mengenai masa depan dan kehidupan anak-anak mereka.

Dalam penelitian ini mayoritas subjek sudah menikah, sehingga gangguan ini kemungkinan disebabkan oleh kesulitan dalam menghadapi keadaan dalam kehidupan pernikahan. Berbagai kebiasaan dan gaya hidup yang harus disesuaikan setelah seseorang menjalani pernikahan dapat memicu gangguan ansietas menyeluruh.

Dari hasil analisis tersebut juga tidak terdapat hubungan yang bermakna status pekerjaan dengan gangguan ansietas menyeluruh. Keadaaan ini bertentangan dengan penelitian oleh AlSaffar dan Saeed $^{7}$ yang menyatakan terdapat hubungan antara status pekerjaan dan gangguan ansietas menyeluruh. Pada penelitian tersebut, status pekerjaan terbanyak tidak bekerja karena mungkin sebagai hasil kesulitan yang dihadapi orang yang tidak bekerja dalam kehidupan seharihari dan keluarganya. Juga besar biaya hidup dan memikirkan masa depan diri, anak-anak, serta bagaimana muncul rasa ketakutan bahwa mereka tidak akan mampu mengurus diri mereka sendiri di masa yang akan datang.

Pada penelitian lain juga telah dilaporkan bahwa pasien gangguan ansietas menyeluruh lebih khawatir mengenai masa depannya daripada gangguan ansietas lain. ${ }^{16}$

Simpulan, ditemukan proporsi yang cukup besar gangguan ansietas menyeluruh di klinik psikiatri sehingga diharapkan tenaga medis dan masyarakat awam dapat lebih jeli mengenali gangguan ansietas agar Indonesia terbebas dari penyakit kesehatan mental di masa yang akan datang.

\section{Daftar Pustaka}

1. Sadock BJ, Sadock VA. Kaplan and Sadock's synopsis of psychiatry. Edisi ke-10. Philadelphia: Lippincott Williams \& Wilkins; 2007.

2. Departemen Kesehatan Republik Indonesia. Pedoman penggolongan dan diagnosis gangguan jiwa di Indonesia III (PPDGJ III). Jakarta: Departemen Kesehatan RI; 1993.

3. Khan H, Kalia S, Itrat A, Khan A, Kamal M, Khan MA, dkk. Prevalence and demographics of anxiety disorders: a snapshot from a community health centre in Pakistan. Annals General Psychiatry. 2007;30:1-6.

4. Lieb R, Becker E, Altamura C. The epidemiology of generalized anxiety disorder in Europe. Eur Neuropsychopharmacol. 2005; 15:445-52.

5. Araya R, Rojas G, Fritsch R, Acuna J, Lewis G. Common mental disorders in Santiago, Chile: prevalence and socio-demographic correlates. Br J Psychiatry. 2001;178:228-33.

6. Yonkers KA, Warshaw MG, Massion AO, Keller MB. Phenomenology and course of generalized anxiety disorder. Br J Psychiatry. 
1996;168:308-13.

7. Al-Saffar NM, Saeed DA. Generalized anxiety disorder in type 2 diabetes mellitus in Suleimaniya city. Tikrit Med J. 2009;15(1):78-85.

8. Lecrubier Y, Sheehan D, Weiller E, Janavs J, Amorium P, Knapp E, dkk. Mini International Neuropsychiatric Interview version ICD10;1998; Pelatihan kandidat gen skizofrenia di Indonesia; 2009.

9. Anfasha F, Primastari E, Runtulalo F, Irdam GA, Priyonugroho G, Hastiningsih W, dkk. Uji tapis depresi menggunakan MINI ICD10 dan faktor-faktor yang berhubungan pada pasien dengan keganasan ginekologi di Rumah Sakit Dr. Cipto Mangunkusumo Jakarta. Indones J Obstet Gynecol. 2008;323:167-71.

10. Ansari AA, Alaiwat BA, Hamadeh R, Ali M, Mukarim B, Othman R. Treatment and prevalence of generalized anxiety disorder and depression among primary care attendees. Bahrain Med Bull. 2010 March;32(1):1-5.

11. Sheehan DV, Lecrubier Y, Sheehan KH, Amorim P, Janavs J, Weiler E, dkk. The MiniInternational Neuropsychiatric Interview (M.I.N.I.): the development and validation of a structural diagnostic psychiatric interview for DSM-IV and ICD-10. J Clin Psychiatry. 1998;59(suppl 20):22-33.

12. Otsubo T, Tanaka K, Koda R, Shinoda J, Sano $\mathrm{N}$, Tanaka S, dkk. Reliability and validity of
Japanese version of the Mini-International Neuropsychiatric Interview. Psychiatry Clinic Neurosci. 2005;59:517-26.

13. Jones JE, Hermann BP, Barry JJ, Gilliam F, Kanner AM, Meador KJ. Clinical assessment of axis I psychiatric morbidity in chronic epilepsy: a multicenter investigation. J Neuropsychiatry Clinic Neurosci. 2005; 17:172-9.

14. Hidayat D, Ingkiriwang E, Andri, Asnawi E, Widya RS, Susanto DH. Penggunaan metode dua menit (M2M) dalam menentukan prevalensi gangguan jiwa di pelayanan primer. Maj Kedokt Indon. 2010;60(10):44854.

15. Scott KM, Wells JE, Angermayer M, Brugha TS, Bromet E, Demyttenaere K, dkk. Gender and the relationship between marital status and first onset of mood, anxiety and substance use disorders. Psychol Med. 2010;40(9):1495-505.

16. Kessler RC, Walters EE, Wittchen H. Epidemiology. Dalam: Heimberg RG, Turk CL, Mennin DS, penyunting. Generalized anxiety disorder, advances in research and practice. New York: The Guilford Press. 2004. hlm. 29-50.

17. Yonkers KA, Dyck IR, Warshaw M, Keller MB. Factors predicting the clinical course of generalized anxiety disorder. Br J Psychiatry. 2000;176:544-9. 